ARTICLE

\title{
Six-photon upconverted excitation energy lock-in for ultraviolet-C enhancement
}

\author{
Qianqian Su (1) 1,6凶, Han-Lin Wei ${ }^{1,6}$, Yachong Liu', Chaohao Chen (1) ${ }^{2}$, Ming Guan ${ }^{3}$, Shuai Wang ${ }^{1}$, Yan Su${ }^{4}$, \\ Haifang Wang ${ }^{1 凶}$, Zhigang Chen ${ }^{5}$ \& Dayong Jin ${ }^{2,3 凶}$
}

Photon upconversion of near-infrared (NIR) irradiation into ultraviolet-C (UVC) emission offers many exciting opportunities for drug release in deep tissues, photodynamic therapy, solid-state lasing, energy storage, and photocatalysis. However, NIR-to-UVC upconversion remains a daunting challenge due to low quantum efficiency. Here, we report an unusual six-photon upconversion process in $\mathrm{Gd}^{3+} / \mathrm{Tm}^{3+}$-codoped nanoparticles following a heterogeneous core-multishell architecture. This design efficiently suppresses energy consumption induced by interior energy traps, maximizes cascade sensitizations of the NIR excitation, and promotes upconverted UVC emission from high-lying excited states. We realized the intense six-photon-upconverted UV emissions at $253 \mathrm{~nm}$ under $808 \mathrm{~nm}$ excitation. This work provides insight into mechanistic understanding of the upconversion process within the heterogeneous architecture, while offering exciting opportunities for developing nanoscale UVC emitters that can be remotely controlled through deep tissues upon NIR illumination.

\footnotetext{
${ }^{1}$ Institute of Nanochemistry and Nanobiology, Shanghai University, Shanghai, People's Republic of China. ${ }^{2}$ Institute for Biomedical Materials \& Devices (IBMD), Faculty of Science, University of Technology Sydney, Sydney, NSW, Australia. ${ }^{3}$ UTS-SUStech Joint Research Centre for Biomedical Materials \& Devices, Department of Biomedical Engineering, Southern University of Science and Technology, Shenzhen, Guangdong 518055, People's Republic of China. ${ }^{4}$ Genome Institute of Singapore, Agency of Science Technology and Research, Singapore City, Singapore. ${ }^{5}$ State Key Laboratory for Modification of Chemical Fibers and Polymer Materials, College of Materials Science and Engineering, Donghua University, Shanghai, People's Republic of China. ${ }^{6}$ These authors contributed equally: Qianqian Su, Han-Lin Wei. ${ }^{凶}$ email: chmsqq@shu.edu.cn; hwang@shu.edu.cn; dayong.jin@uts.edu.au
} 
M ultiphoton upconversion processes that convert NIR excitation into visible emissions have attracted considerable attention owing to broad technical applications of anti-Stokes shifts ${ }^{1-6}$. UV upconversion luminescence can be a powerful tool for applications in biomedical $^{7-9}$, environmental ${ }^{10,11}$, and industrial fields ${ }^{12,13}$, and converting NIR all the way upto UVC (100-290 nm) emissions holds promise in photocatalysis $^{11}$, ultraviolet solid-state lasers ${ }^{12}$, and biomedical applications ${ }^{8,14-17}$. But, their practical implementations have been hindered by low emission intensities and difficulties in achieving large shifts into the UVC region. Apart from the intrinsic parity-forbidden nature of $4 \mathrm{f}-4 \mathrm{f}$ optical transitions in lanthanide systems, NIR-to-UVC upconversion can be significantly influenced by many deleterious factors, such as concentration quenching, surface quenching, cross-relaxation between lanthanide ions, and competitive energy harvesting from lower-lying energy levels. To minimize the unwanted energy consumption at high-lying emitting levels and reduce the chances for mitigating the upconverted UV emissions, attempts have been made to enhance the emission intensity in the UV range, for instance, by controlling the particle phase and size ${ }^{18}$, the pulse width of excitation beams ${ }^{19}$, dopant composition ${ }^{20}$, and nanoparticle core-shell structures ${ }^{12,21-24}$. To our best knowledge, little attention has been paid to the effect of interior defects on UVC upconversion luminescence $\mathrm{e}^{25}$.

Compared with $\mathrm{Yb}^{3+}$-sensitized upconversion nanoparticles

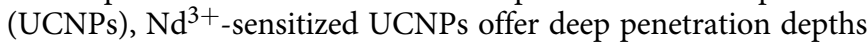
and minimal over-heating effect, owing to low coefficients of water absorption under $800-\mathrm{nm}$ excitation ${ }^{26} . \mathrm{Nd}^{3+}$-sensitized UCNPs are the promising candidates for photon-driven reactions in biosystems, such as biodetection ${ }^{27}$, photodynamic therapy ${ }^{28-31}$, light-triggered drug release ${ }^{32}$, and photocatalysis ${ }^{33}$. To enhance the brightness of $\mathrm{Nd}^{3+}$-sensitized UCNPs, core-shell nanostructural design has been typically utilized to prevent deleterious cross-relaxation ${ }^{34-37}$. By doping lanthanide ions and $\mathrm{Nd}^{3+}$ ions into the separated layer, the emission intensity can be notably enhanced while maintaining optical integrity ${ }^{38}$. Despite enticing prospects, UVC emission from $\mathrm{Nd}^{3+}$-sensitized UCNPs has been challenging because of the densely packed excited states of $\mathrm{Nd}^{3+}$ and dominant cross-relaxation within the nanoscale systems ${ }^{39}$.

Here we report the significantly enhanced UVC emission through $\mathrm{Nd}^{3+}$ sensitization by controlling upconverted excitation energy flux within $\mathrm{Gd}^{3+} / \mathrm{Tm}^{3+}$ codoped core and multishell nanostructures. Our mechanistic investigation reveals an upconverted excitation lock-in (UCEL) mode in which $\mathrm{Gd}^{3+}$-sensitized excitation energy can be retained by simply using an interlayer of the $\mathrm{NaYF}_{4}$ host lattice doped with $\mathrm{Yb}^{3+}$ that is optically inert to the excited $\mathrm{Gd}^{3+}$. This nanostructure preserves the upconverted UV energy within the core domain and effectively suppresses energy dissipation by interior traps, enabling six-photonupconverted UV emission at $253 \mathrm{~nm}$ under $808 \mathrm{~nm}$ excitation.

\section{Results}

Heterogeneous nanostructural design. In our experiment, we designed a heterogeneous core-multishell structure to suppress surface quenching and achieve tunable emissions. In a conventional design ${ }^{35,40}$, under $808-\mathrm{nm}$ excitation, $\mathrm{Nd}^{3+}$ sensitizers harvest excitation photons and subsequently pass them to $\mathrm{Yb}^{3+}$ ions with an excited state at $\sim 10000 \mathrm{~cm}^{-1}$. Energy migration through a network of high concentration $\mathrm{Yb}^{3+}$ ions promotes energy transfer of the NIR excitation to $\mathrm{Tm}^{3+}$ emitters with ladder-like metastable intermediate states, facilitating sequential upconversion processes from NIR to visible/UV. Subsequently, upconverted UV emission from high-lying states of $\mathrm{Tm}^{3+}$ can be

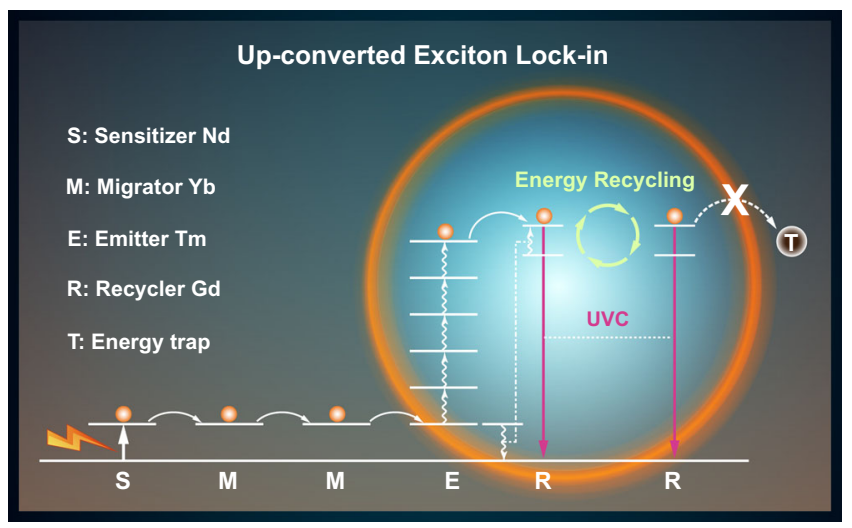

Fig. 1 Schematic illustration of upconverted excitation lock-in (UCEL) mechanism for UVC generation within a nanoparticle. The proposed UCEL scheme involving a heterogeneous, core-multishell nanostructure (Gd$\left.\mathrm{CS}_{\mathrm{Y}} \mathrm{S}_{2} \mathrm{~S}_{3}\right)$. A multistep cascade energy transfer $\left(\mathrm{Nd}^{3+} \rightarrow \mathrm{Yb}^{3+} \rightarrow \mathrm{Tm}^{3+} \rightarrow \mathrm{Gd}^{3+}\right)$ leads to populate the excited states of $\mathrm{Gd}^{3+}$. The layer of an optical inert $\mathrm{NaYF}_{4}$ host lattice doped with $20 \% \mathrm{Yb}^{3+}$ locating in the first shell layer of nanoparticles can lock-in the upconverted excitation energy of $\mathrm{Gd}^{3+}$ ions and prevent depopulation by deleterious energy traps within the nanoparticles, resulting in intense UVC upconversion emission. S, M, E, R, and T denote sensitizer $\mathrm{Nd}^{3+}$, migrator $\mathrm{Yb}^{3+}$, emitter $\mathrm{Tm}^{3+}$, recycler $\mathrm{Gd}^{3+}$, and energy traps, respectively.

further transferred to $\mathrm{Gd}^{3+}$ ions embedded in the nanoparticle core as the UVC energy reservoirs.

The key to our design is the use of a $\mathrm{NaYF}_{4}$ host lattice doped with the same amount of $\mathrm{Yb}^{3+}$ locating in the first shell layer of $\mathrm{NaGdF}_{4}: 49 \% \mathrm{Yb}, 1 \% \mathrm{Tm} @ \mathrm{NaGdF}_{4}: 20 \% \mathrm{Yb} @ \mathrm{NaGdF}_{4}: 10 \% \mathrm{Yb}, 50 \%$ $\mathrm{Nd} @ \mathrm{NaGdF}_{4}\left(\mathrm{Gd}-\mathrm{CS}_{\mathrm{Gd}} \mathrm{S}_{2} \mathrm{~S}_{3}\right)$ nanoparticle (Fig. 1). This layer of $\mathrm{NaYF}_{4}: 20 \% \mathrm{Yb}$ is optically inert to the excited states $\left({ }^{6} \mathrm{D}_{\mathrm{J}},{ }^{6} \mathrm{I}_{\mathrm{J}}\right.$, and $\left.{ }^{6} \mathrm{P}_{\mathrm{J}}\right)$ of $\mathrm{Gd}^{3+}$ ions and can lock-in the upconverted UVC and ultraviolet-B (UVB) energy of $\mathrm{Gd}^{3+}$ ions. The $\mathrm{Gd}^{3+}$ network can then reuse the upconverted excitation energy and prevent depopulation by deleterious energy traps within the nanoparticles, as well as absorb additional photon energy from the excited state $\mathrm{Yb}^{3+}$ ions. The $\mathrm{NaYF}_{4}$ layer plays a key role in interdicting detrimental energy transfer between $\mathrm{Gd}^{3+}$ and interior traps, enhancing five- and six-photon-upconverted UVB and UVC emissions.

Upconverted excitation lock-in (UCEL) mode. The UCEL mode requires both an interlayer of optical inert $\mathrm{NaYF}_{4}$ host lattice doped with $\mathrm{Yb}^{3+}$ and a network of $\mathrm{Gd}^{3+}$ ions to recycle upconversion energy for UVC emission amplification. Fig. 2 illustrates a typical upconversion process in the heterogeneous core-multishell nanoparticles upon $808-\mathrm{nm}$ excitation. The $808 \mathrm{~nm}$ photons are first sensitized by $\mathrm{Nd}^{3+}$ sensitizer ions, being populated at the ${ }^{4} \mathrm{~F}_{5 / 2}$ energy state and quickly relaxed to the ${ }^{4} \mathrm{~F}_{3 / 2}$ energy state of $\mathrm{Nd}^{3+}$. The excited $\mathrm{Yb}^{3+}$ ions serve as an energy migrator to sensitize and pass on the energy from $\mathrm{Nd}^{3+}$ and to populate the ${ }^{3} \mathrm{P}_{2}$ state of $\mathrm{Tm}^{3+}$ through a five-photon upconversion process. Subsequently, the energy at the ${ }^{3} \mathrm{P}_{2}$ state, relax non-radiatively to populate ${ }^{1} \mathrm{I}_{6}$ and give rise to $\mathrm{UVB}$ emissions at $290 \mathrm{~nm}$. Besides, $\mathrm{Gd}^{3+}$ ions in the core domain extract the energy through an energy transfer process of ${ }^{1} \mathrm{I}_{6} \rightarrow{ }^{3} \mathrm{H}_{6}\left(\mathrm{Tm}^{3+}\right):{ }^{8} \mathrm{~S}_{7 / 2} \rightarrow{ }^{6} \mathrm{P}_{\mathrm{J}}\left(\mathrm{Gd}^{3+}\right)$. The excitation energy of $\mathrm{Gd}^{3+}$ at ${ }^{6} \mathrm{P}_{\mathrm{J}}$ can resist nonradiative quenching due to its large energy gap $\left(\sim 32000 \mathrm{~cm}^{-1}\right.$ from ${ }^{6} \mathrm{P}_{\mathrm{J}}$ to $\left.{ }^{8} \mathrm{~S}_{7 / 2}\right)$. Thus, the lifetime of $\mathrm{Gd}^{3+}$ at ${ }^{6} \mathrm{P}_{\mathrm{J}}$ energy state is long enough for the sixth photon to be absorbed from the excited $\mathrm{Yb}^{3+}$. Therefore, the ${ }^{6} \mathrm{D}_{\mathrm{J}}$ state of $\mathrm{Gd}^{3+}$ is further populated by the appropriate energy matching of the following transitions of ${ }^{2} \mathrm{~F}_{5 / 2} \rightarrow{ }^{2} \mathrm{~F}_{7 / 2}\left(9750 \mathrm{~cm}^{-1}, \mathrm{Yb}^{3+}\right):{ }^{6} \mathrm{P}_{\mathrm{J}} \rightarrow{ }^{6} \mathrm{D}_{\mathrm{J}}$ 


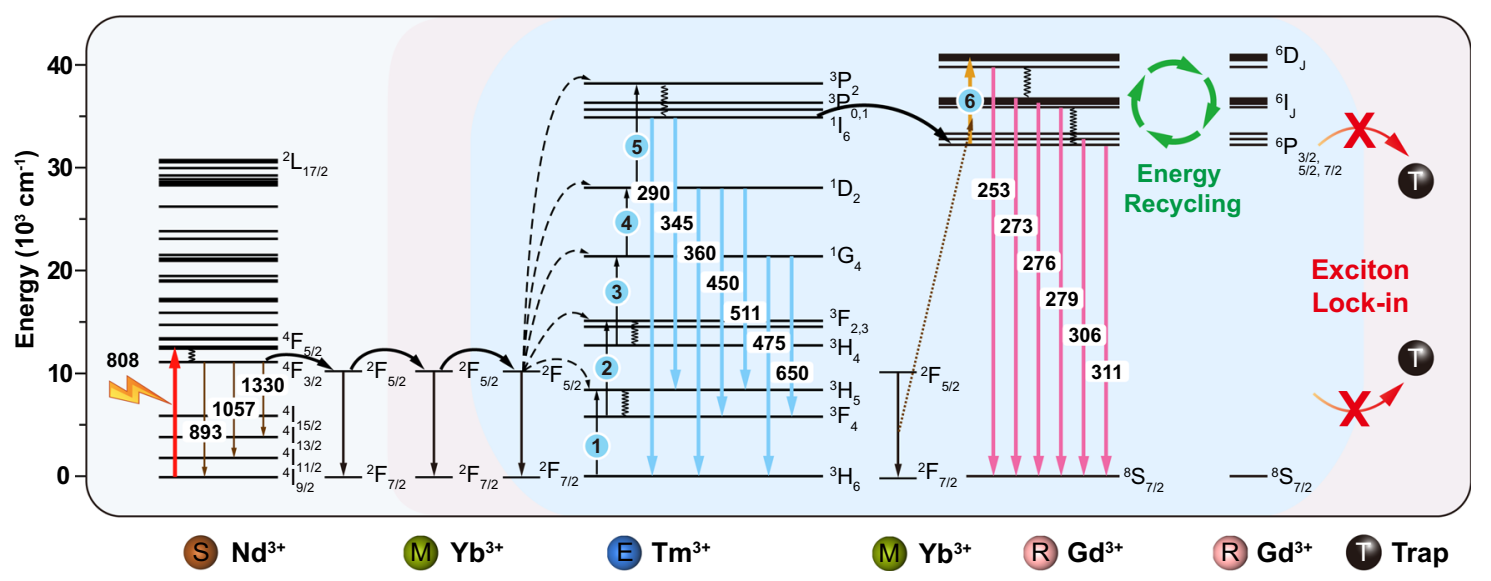

Fig. 2 Schematic energy diagram of heterogeneously doped lanthanide ions and their cascade energy transfer within a core-multishell nanoparticle. When the nanoparticles are excited under $808 \mathrm{~nm}, \mathrm{Nd}^{3+}$ sensitizers first absorb the excitation energy and pass it onto $\mathrm{Yb}^{3+}$. Subsequently, the ${ }^{3} \mathrm{P}_{2}$ state of $\mathrm{Tm}^{3+}$ is populated by a sequential five-photon energy transfer from the network of excited $\mathrm{Yb}^{3+}$ ions and relaxes to ${ }^{1} \mathrm{I}_{6}$. The ${ }^{6} \mathrm{D}_{\mathrm{J}}$ state of $\mathrm{Gd} \mathrm{d}^{3+}$ is populated via a stepwise process of a five-photon energy transfer process from $\mathrm{Tm}^{3+}$ and a further energy transfer from $\mathrm{Yb}^{3+}$, giving rise to the sixth-photon upconversion luminescence. The inert $\mathrm{NaYF}_{4}$ host lattice layer can lock-in the $\mathrm{Gd}^{3+}$ excitation energy and reuse the energy that would otherwise be depopulated by deleterious energy traps within the nanoparticles, resulting in upconversion emissions in the UVB and UVC regions.

$\left(\sim 8750 \mathrm{~cm}^{-1}, \mathrm{Gd}^{3+}\right)^{41-43}$. Thus, UVC and UVB upconversion emission peaked at $253,273,276,279,306$, and $311 \mathrm{~nm}$ from ${ }^{6} \mathrm{D}_{\mathrm{J}}$, ${ }^{6} \mathrm{I}_{\mathrm{J}}$, and ${ }^{6} \mathrm{P}_{\mathrm{J}}$ of $\mathrm{Gd}^{3+}$ can be obtained. Noted that, the probability of nonradiative relaxation of ${ }^{6} \mathrm{D}_{\mathrm{J}},{ }^{6} \mathrm{I}_{\mathrm{J}} \rightarrow{ }^{6} \mathrm{P}_{\mathrm{J}}$ is larger than that of the radiative transition of ${ }^{6} \mathrm{D}_{\mathrm{J}},{ }^{6} \mathrm{I}_{\mathrm{J}} \rightarrow{ }^{8} \mathrm{~S}_{7 / 2}$, resulting in an efficient population of the ${ }^{6} \mathrm{P}_{7 / 2}$ state, commonly observed in Gd-based homogeneous nanostructures ${ }^{22}$. In our design, the $\mathrm{NaYF}_{4}$-based first shell layer selectively blocks the energy transfer from $\mathrm{Gd}^{3+}$ to interior energy traps (e.g., lattice defects and impurities). It preserves and recycles the excitation energy within the core region, leading to increased populations in the ${ }^{6} \mathrm{D}_{\mathrm{J}},{ }^{6} \mathrm{I}_{\mathrm{J}}$, and ${ }^{6} \mathrm{P}_{\mathrm{J}}$ states of $\mathrm{Gd}^{3+}$ and intense UVC and UVB emissions of $\mathrm{Gd}^{3+}$.

Controlled synthesis. We used a layer-by-layer epitaxial growth method $^{24}$ to synthesize a batch of Gd-CS $\mathrm{S}_{2} \mathrm{~S}_{3}$ nanoparticles with optimized concentrations of co-dopants ${ }^{40}$ following the design of $\mathrm{NaGdF}_{4}: 49 \% \mathrm{Yb}, 1 \% \mathrm{Tm} @ \mathrm{NaYF}_{4}: 20 \% \mathrm{Yb} @ \mathrm{NaGdF}_{4}: 10 \% \mathrm{Yb}, 50 \%$ $\mathrm{Nd@NaGdF}$ (Fig. 3a). Transmission electron microscopy (TEM) images of obtained $\mathrm{Gd}-\mathrm{CS}_{\mathrm{Y}} \mathrm{S}_{2} \mathrm{~S}_{3}$ nanoparticles show the average size of $\sim 29 \mathrm{~nm}$ with each layer $\sim 2.5 \mathrm{~nm}$ in thickness (Supplementary Fig. 1). High-resolution TEM shows the single-crystalline structure of the as-synthesized core-multishell nanoparticles (Fig. 3b inset), and X-ray powder diffraction result (XRD, JCPDS file number 270699, Supplementary Fig. 2) confirms the hexagonal phase of the as-prepared nanoparticles. High-angle annular darkfield scanning TEM identified the formation of the heterogeneous core-multishell structures (Fig. 3b), in which the brighter regions correspond to heavier elements $(\mathrm{Gd}, \mathrm{Yb}$, and $\mathrm{Nd}$ ) and the darker parts correspond to lighter ones $(\mathrm{Y})$. Energy-dispersive $\mathrm{X}$-ray mapping analysis further confirms the heterogeneous core-multishell structures (Fig. 3c and Supplementary Fig. 3).

Remarkable UVC enhancement. To investigate the unusual UVC upconversion emission from $\mathrm{Gd}^{3+}$, we recorded the photoluminescence spectra of the as-synthesized nanoparticles at room temperature. Usually, in favor of the lower ${ }^{6} \mathrm{P}_{7 / 2}(311 \mathrm{~nm})$ energy level, the $\mathrm{Gd}^{3+}$ emission in the UVC range is quenched, and optical transitions of $\left({ }^{6} \mathrm{D}_{\mathrm{J}}, \quad{ }^{6} \mathrm{I}_{\mathrm{J}}, \quad{ }^{6} \mathrm{P}_{5 / 2} \rightarrow{ }^{8} \mathrm{~S}_{7 / 2}\right)$ could hardly be spectroscopically detected (Supplementary Figs. 4-7) ${ }^{12}$. In contrast, as shown in Fig. 3d and Supplementary Fig. 8, intense upconversion emissions from ${ }^{6} \mathrm{D}_{\mathrm{J}}$ and ${ }^{6} \mathrm{I}_{\mathrm{J}}$ of $\mathrm{Gd}^{3+}$ peaked at $253 \mathrm{~nm}\left({ }^{6} \mathrm{D}_{9 / 2} \rightarrow{ }^{8} \mathrm{~S}_{7 / 2}\right), 273 \mathrm{~nm}\left({ }^{6} \mathrm{I}_{\mathrm{J}} \rightarrow{ }^{8} \mathrm{~S}_{7 / 2}\right), 276 \mathrm{~nm}\left({ }^{6} \mathrm{I}_{\mathrm{J}} \rightarrow{ }^{8} \mathrm{~S}_{7 / 2}\right)$,
$279 \mathrm{~nm}\left({ }^{6} \mathrm{I}_{\mathrm{J}} \rightarrow{ }^{8} \mathrm{~S}_{7 / 2}\right), 306 \mathrm{~nm}\left({ }^{6} \mathrm{P}_{5 / 2} \rightarrow{ }^{8} \mathrm{~S}_{7 / 2}\right)$ and $311 \mathrm{~nm}\left({ }^{6} \mathrm{P}_{7 / 2} \rightarrow\right.$ $\left.{ }^{8} S_{7 / 2}\right)$ in the UV region were observed either under $808 \mathrm{~nm}$ or 980 nm excitation. Moreover, we observed more than 50-fold and 30 fold enhancements in $\mathrm{Gd}^{3+}$ emission $(311 \mathrm{~nm})$ by our $\mathrm{Gd}-\mathrm{CS}_{\mathrm{Y}} \mathrm{S}_{2} \mathrm{~S}_{3}$ heterogeneous core-multishell design compared with the conventional Gd- $\mathrm{CS}_{\mathrm{Gd}_{2}} \mathrm{~S}_{2} \mathrm{~S}_{3}$ nanoparticles under 808 and $980 \mathrm{~nm}$ excitation, respectively (Supplementary Figs. 9 and 10), although the absorption profile of Gd-CS $\mathrm{S}_{2} \mathrm{~S}_{3}$ is not changed compared with that of Gd-CS $\mathrm{Gd}_{\mathrm{Gd}_{2}} \mathrm{~S}_{3}$ nanoparticles (Supplementary Fig. 11). The approximate absorption cross-section $\sigma$ of $\mathrm{Nd}^{3+}$ at $808 \mathrm{~nm}$ was calculated to be $\sigma=1.5 \times 10^{-19} \mathrm{~cm}^{2}\left(\mathrm{Gd}-\mathrm{CS}_{\mathrm{Y}} \mathrm{S}_{2} \mathrm{~S}_{3}\right), \quad \sigma=1.3 \times 10^{-19} \mathrm{~cm}^{2}$ $\left(\mathrm{Gd}-\mathrm{CS}_{\mathrm{Gd}} \mathrm{S}_{2} \mathrm{~S}_{3}\right)$ from the $\mathrm{UV}-\mathrm{V}$ is absorption spectra of the nanoparticles ${ }^{44}$. As verified by the emission spectra of as-prepared nanoparticles from different batches of (Supplementary Fig. 12), our protocol to enhance the UVC upconversion emissions is reproducible.

We further studied the excitation power dependence of luminescence intensity from higher-lying ${ }^{6} \mathrm{D}_{\mathrm{J}},{ }^{6} \mathrm{I}_{\mathrm{J}}$ and ${ }^{6} \mathrm{P}_{\mathrm{J}}$ excited states of $\mathrm{Gd}^{3+}$ (Fig. 3f). The number of photons $(n)$ required to populate the upper emitting state can be calculated by the luminescence intensity $I_{f}$, and the pump power of laser $P$ following the relation of $I_{f} \propto P^{n 45}$. The output slope for $253 \mathrm{~nm}$ emission band was calculated as 6.29 , indicating that six $808 \mathrm{~nm}$ photons were needed to populate the ${ }^{6} \mathrm{D}_{\mathrm{J}}$ level, following a six photon upconversion process (Fig. $3 \mathrm{~g}$ ), while $n$ values obtained for 276 and $311 \mathrm{~nm}$ emissions were 5.27 and 4.94, indicating fivephoton processes (Supplementary Fig. 13).

Quantitative study. The large energy gap of about $32000 \mathrm{~cm}^{-1}$ of $\mathrm{Gd}^{3+}$ and intrinsic low phonon energy of $\mathrm{NaGdF}_{4}$ offer good possibilities to obtain $100 \%$ energy transfer efficiency from $\mathrm{Gd}^{3+}$-to$\mathrm{Gd}^{3+46,47}$. The energy transfer efficiencies $\eta$ of $\mathrm{Nd}^{3+}-$ to- $\mathrm{Yb}^{3+}$, $\mathrm{Yb}^{3+}$-to- $\mathrm{Tm}^{3+}$, and $\mathrm{Tm}^{3+}$-to-Gd ${ }^{3+}$ energy transfer can be quantitatively estimated from the Eqs. 1 and $2^{48,49}$

$$
\begin{gathered}
\eta=1-\frac{\tau_{m}}{\tau_{\mathrm{Ln}}} \\
\tau_{\mathrm{m}}=\frac{\sum \alpha_{i} \tau_{i}^{2}}{\sum \alpha_{i} \tau_{\mathrm{i}}}
\end{gathered}
$$

where $\tau_{\mathrm{m}}$ is the mean lifetime of energy donor lanthanides (Ln) in the presence of energy acceptor, $\tau_{\mathrm{Ln}}$ is the intrinsic lifetime of energy 


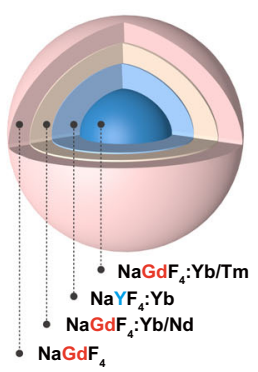

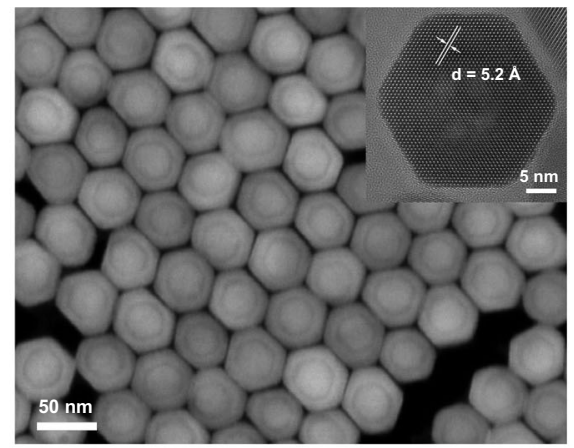
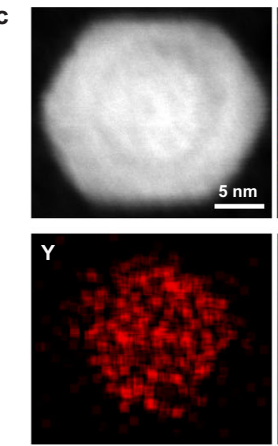
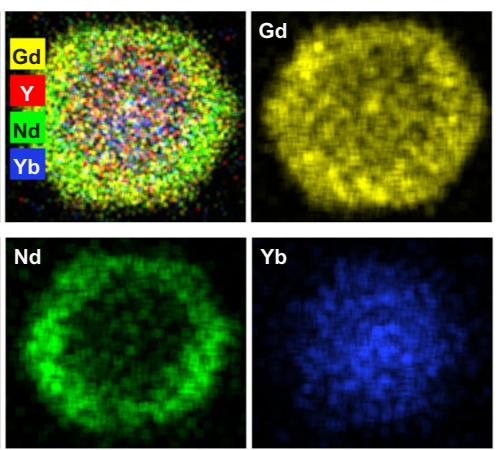
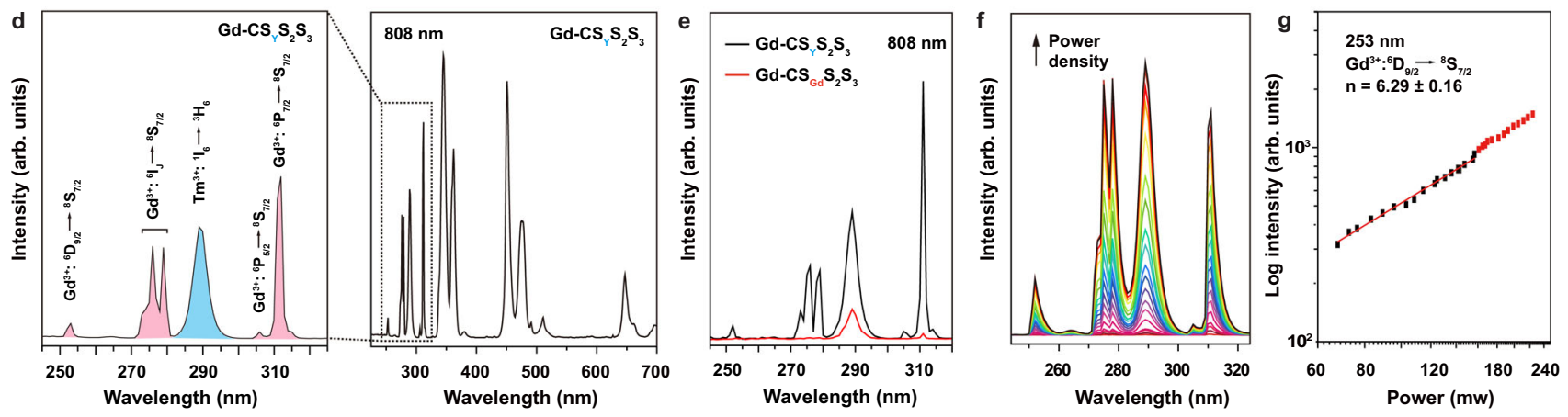

Fig. 3 Structural and optical characterizations of $\mathbf{G d}-\mathbf{C S}_{\mathbf{Y}} \mathbf{S}_{\mathbf{2}} \mathbf{S}_{\mathbf{3}}$ nanoparticles before and after cation exchange. a Schematic illustration of the assynthesized $\mathrm{Gd}-\mathrm{CS}_{Y} \mathrm{~S}_{2} \mathrm{~S}_{3}$ nanoparticles. b High-angle annular dark-field scanning transmission electron microscopy (HAADF-STEM) image and highresolution TEM image of the corresponding nanoparticles (inset). c HAADF-STEM image and elemental mapping of a single Gd-CSY $\mathrm{S}_{2} \mathrm{~S}_{3}$ nanoparticle, indicating the spatial distribution of the $\mathrm{Gd}, \mathrm{Y}, \mathrm{Nd}$, and $\mathrm{Yb}$ elements in the core-multishell structure. $\mathbf{d}$ Room-temperature emission spectra of $\mathrm{Gd}-\mathrm{CS}_{Y} \mathrm{~S}_{2} \mathrm{~S}_{3}$ nanoparticles in cyclohexane under $808 \mathrm{~nm}$ excitation. e Emission spectra of $\mathrm{Gd}-\mathrm{CS}_{Y} \mathrm{~S}_{2} \mathrm{~S}_{3}$ and $\mathrm{Gd}_{-}-\mathrm{CS}_{\mathrm{Gd}} \mathrm{S}_{2} \mathrm{~S}_{3}$ under excitation of $808 \mathrm{~nm}$ $\mathrm{CW}$ diode laser. The excitation power density is $10 \mathrm{~W} \mathrm{~cm}-2$. $\mathbf{f}$ Excitation-power-dependent UV upconversion emission spectra of $\mathrm{Gd}_{-} \mathrm{C}_{\mathrm{Y}} \mathrm{S}_{2} \mathrm{~S}_{3}$ nanoparticles under $808 \mathrm{~nm}$ excitation. $\mathbf{g}$ Log intensity-pump power of the $253 \mathrm{~nm}$ upconversion emission of $\mathrm{Gd}_{-} \mathrm{C}_{Y} \mathrm{~S}_{2} \mathrm{~S}_{3}$ nanoparticles under $808 \mathrm{~nm}$ excitation.

donor, and $\alpha$ is the amplitude. To calculate the energy transfer efficiencies of $\mathrm{Nd}^{3+}$-to- $\mathrm{Yb}^{3+}, \mathrm{Yb}^{3+}$-to- $\mathrm{Tm}^{3+}$, and $\mathrm{Tm}^{3+}$-to- $\mathrm{Gd}^{3+}$, we designed and synthesized three pairs of heterogeneous nanoparticles (TEM results shown in Supplementary Fig. 14). In our experiment, to first determine the intrinsic lifetime of the corresponding energy donors, the energy acceptors of $\mathrm{Yb}^{3+}, \mathrm{Tm}^{3+}$, and $\mathrm{Gd}^{3+}$ were replaced by optically inert $\mathrm{Y}^{3+}$ ions.

In detail, to calculate the energy transfer efficiency of $\mathrm{Nd}^{3+}$-to$\mathrm{Yb}^{3+}$, we produced a pair of samples of $\mathrm{NaGdF}_{4}: 49 \% \mathrm{Yb}, 1 \%$ Tm@NaYF $: 20 \% \mathrm{Yb} @ \mathrm{NaGdF}_{4}: 10 \% \mathrm{Yb}, 50 \% \mathrm{Nd} @ \mathrm{NaGdF}_{4} \quad$ (Gd$\mathrm{CS}_{\mathrm{Y}} \mathrm{SS}$ in the presence of $20 \% \mathrm{Yb}^{3+}$ energy acceptor) v.s. $\mathrm{NaGdF}_{4}: 49 \% \mathrm{Y}, 1 \% \mathrm{Tm} @ \mathrm{NaYF}_{4} @ \mathrm{NaGdF}_{4}: 10 \% \mathrm{Y}, 50 \% \mathrm{Nd} @ \mathrm{NaGdF}_{4}$ $\left(\mathrm{Gd}-\mathrm{CS}_{\mathrm{Y}} \mathrm{SS}\right.$ in the absence of $\left.20 \% \mathrm{Yb}^{3+}\right)$. The lifetimes of $\mathrm{Nd}^{3+}$ at $893 \mathrm{~nm}$ were measured under the $793 \mathrm{~nm}$ pulsed excitation, and the energy transfer efficiency of $\mathrm{Nd}^{3+}$-to- $\mathrm{Yb}^{3+}$ was calculated to be $79 \%$ (Fig. 4a). Similarly, to calculate the energy transfer efficiency of $\mathrm{Yb}^{3+}$-to- $\mathrm{Tm}^{3+}$, and to avoid the complex energy transfer pathways in the core-multishell structure, we produced a pair of simplified designs of $\mathrm{NaGdF}_{4}: 20 \% \mathrm{Yb}, 1 \% \mathrm{Tm}, 29 \%$ $\mathrm{Y} @ \mathrm{NaYF}_{4}\left(\mathrm{Gd}-\mathrm{CS}_{\mathrm{Y}}\right.$ in the presence of $1 \% \mathrm{Tm}^{3+}$ energy acceptor) v.s. $\mathrm{NaGdF}_{4}: 20 \% \mathrm{Yb}, 30 \% \mathrm{Y} @ \mathrm{NaYF}_{4}\left(\mathrm{Gd}-\mathrm{CS}_{\mathrm{Y}}\right.$ in the absence of $\left.\mathrm{Tm}^{3+}\right)$. The $980 \mathrm{~nm}$ decay lifetimes of $\mathrm{Yb}^{3+}$ were measured under the $920 \mathrm{~nm}$ pulsed excitation, and the energy transfer efficiency of $\mathrm{Yb}^{3+}$-to- $\mathrm{Tm}^{3+}$ was estimated to be $62 \%$ (Fig. $4 \mathrm{~b}$ ). To calculate the energy transfer efficieny of $\mathrm{Tm}^{3+}$-to- $\mathrm{Gd}^{3+}$, we produced a pair of samples of $\mathrm{NaGdF}_{4}: 20 \% \mathrm{Yb}, 1 \% \mathrm{Tm}, 29 \%$ $\mathrm{Y} @ \mathrm{NaYF}_{4}\left(\mathrm{Gd}-\mathrm{CS}_{\mathrm{Y}}\right.$ in the presence of $\left.\mathrm{Gd}^{3+}\right)$ v.s. $\mathrm{NaYF}_{4}: 20 \%$ $\mathrm{Yb}, 1 \% \mathrm{Tm} @ \mathrm{NaYF}_{4}\left(\mathrm{Gd}-\mathrm{CS}_{\mathrm{Y}}\right.$ in the absence of $\left.\mathrm{Gd}^{3+}\right)$. By exciting the samples at $980 \mathrm{~nm}$, the lifetimes of $\mathrm{Tm}^{3+}$ at $290 \mathrm{~nm}$ were

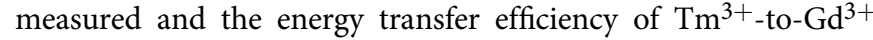
was estimated to be $1 \%$ (Fig. 4c).

Furthermore, we conducted a quantitative study to compare the quantum yields of $\mathrm{Gd}-\mathrm{CS}_{\mathrm{Y}} \mathrm{SS}$ and $\mathrm{Gd}-\mathrm{CS}_{\mathrm{Gd}} \mathrm{SS}$ nanoparticles. The upconversion quantum yields from 240 to $750 \mathrm{~nm}$ of the asprepared $\mathrm{Gd}-\mathrm{CS}_{\mathrm{Y}} \mathrm{S}_{2} \mathrm{~S}_{3}$ and $\mathrm{Gd}-\mathrm{CS}_{\mathrm{Gd}} \mathrm{S}_{2} \mathrm{~S}_{3}$ nanoparticles were estimated as 1.74 and $0.97 \%$, respectively. To quantify the emission enhancement in the UV range from 240 to $325 \mathrm{~nm}$, we also attempted to measure the upconversion quantum yields in the UV range, but without success due to the limited UVC emissions. Instead, we measured the quantum yields of upconversion emissions in the range from 240 to $400 \mathrm{~nm}$, with the results being approximately 0.13 and $0.04 \%$, respectively.

The role of the first layer of $\mathrm{NaYF}_{4}$ shell. To probe the role of $\mathrm{NaYF}_{4}$ layer in locking-in and recycling $\mathrm{Gd}^{3+}$ excitation energy, we have compared the excited state lifetime of $\mathrm{Gd}^{3+}$. As shown in Fig. 5 and Supplementary Fig. 15a significant prolonged ( 4 times) lifetime of $\mathrm{Gd}^{3+}$ emission from the ${ }^{6} \mathrm{P}_{7 / 2}$ level was achieved when the $\mathrm{NaYF}_{4}$ first layer was applied. In contrast, there were negligible changes in the $\mathrm{Gd}^{3+}$ lifetimes for emissions from ${ }^{6} \mathrm{D}_{\mathrm{J}}$ and ${ }^{6} \mathrm{I}_{\mathrm{J}}$ energy levels, indicating the energy loss from $\mathrm{Gd}^{3+}$ to interior energy traps was mainly through ${ }^{6} \mathrm{P}_{7 / 2}$ energy level of $\mathrm{Gd}^{3+}$ due to small energy gap between ${ }^{6} \mathrm{D}_{\mathrm{J}},{ }^{6} \mathrm{I}_{\mathrm{J}}$, and ${ }^{6} \mathrm{P}_{\mathrm{J}}$ (Supplementary Fig. 16). In addition, the emission intensities of $\mathrm{Nd}^{3+}$ at $893 \mathrm{~nm}\left({ }^{4} \mathrm{~F}_{3 / 2} \rightarrow{ }^{4} \mathrm{I}_{9 / 2}\right), 1057 \mathrm{~nm}\left({ }^{4} \mathrm{~F}_{3 / 2} \rightarrow{ }^{4} \mathrm{I}_{11 / 2}\right)$, and $1330 \mathrm{~nm}\left({ }^{4} \mathrm{~F}_{3 / 2} \rightarrow{ }^{4} \mathrm{I}_{13 / 2}\right)$, and $\mathrm{Tm}^{3+}$ at $\sim 1460 \mathrm{~nm}\left({ }^{3} \mathrm{H}_{4} \rightarrow{ }^{3} \mathrm{~F}_{4}\right)$ in the near-infrared range were essentially unaltered (Supplementary Fig. 17). These results indicate that the $\mathrm{NaYF}_{4}$-assisted UCEL 

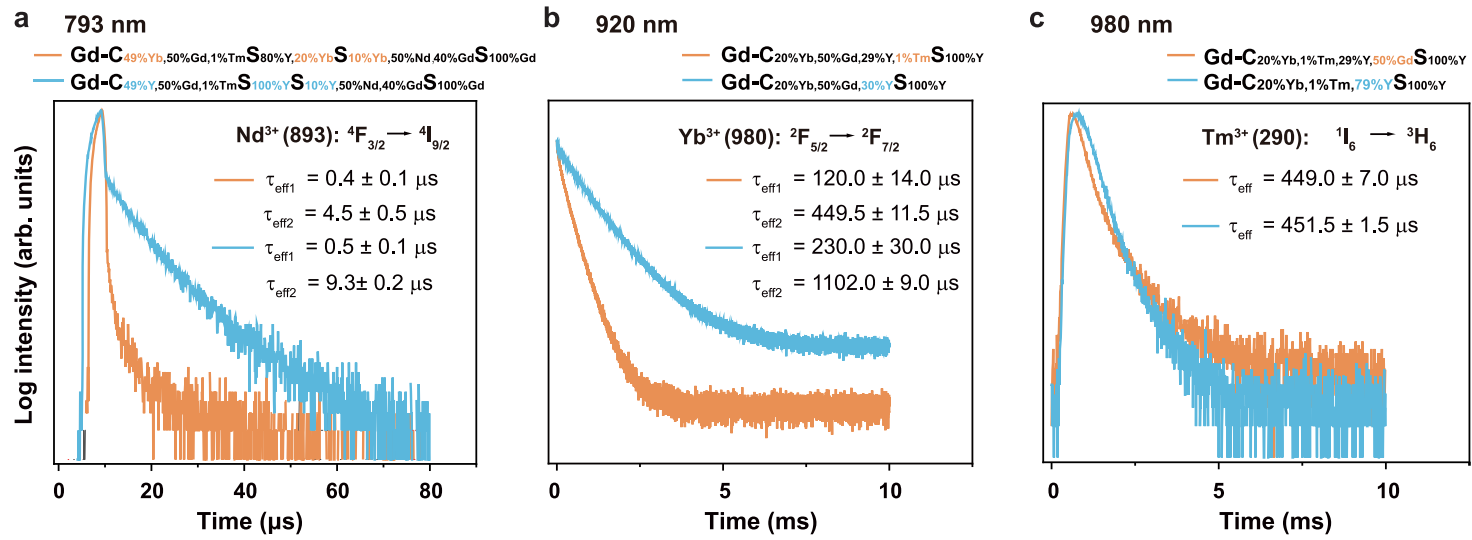

Fig. 4 Lifetime measurements to quantify the step-wise energy transfer efficiencies of from $\mathbf{N d}^{\mathbf{3}+}$ to $\mathbf{Y b}^{\mathbf{3}+}$, from $\mathbf{Y b}^{\mathbf{3}+}$ to $\mathbf{T m}^{\mathbf{3}+}$ and from $\mathrm{Tm}^{\mathbf{3}+}$ to $\mathrm{Gd}^{\mathbf{3}+}$ ion. a Luminescence decay curves of $\mathrm{Nd}^{3+}$ emissions measured at $893 \mathrm{~nm}$ for $\mathrm{NaGdF}_{4}: 49 \% \mathrm{Yb}, 1 \% \mathrm{Tm}_{\mathrm{T}} @ \mathrm{NaYF}_{4}: 20 \% \mathrm{Yb} @ \mathrm{NaGdF}_{4}: 10 \% \mathrm{Yb}_{1}, 50 \% \mathrm{Nd} @ \mathrm{NaGdF}_{4}$ (with $\mathrm{Yb}^{3+}$ ) and $\mathrm{NaGdF}_{4}: 49 \% \mathrm{Y}, 1 \% \mathrm{Tm}_{\mathrm{N}} @ \mathrm{NaYF}_{4} @ \mathrm{NaGdF}_{4}: 10 \% \mathrm{Y}, 50 \% \mathrm{Nd} @ \mathrm{NaGdF}_{4}$ (without $\mathrm{Yb}^{3+}$ ) by pulsed 793 nm excitation. b Luminescence decay curves of $\mathrm{Yb}^{3+}$ emissions measured at $980 \mathrm{~nm}$ for $\mathrm{NaGdF}_{4}: 20 \% \mathrm{Yb}, 1 \% \mathrm{Tm}, 29 \% \mathrm{Y} @ \mathrm{NaYF}_{4}$ (with $\mathrm{Tm}^{3+}$ ) and NaGdF 4 : 20\%Yb,30\%Y@NaYF 4 (without Tm 3 +) by pulsed $920 \mathrm{~nm}$ excitation. c Luminescence decay curves of $\mathrm{Tm}^{3+}$ emissions measured at $290 \mathrm{~nm}$ for NaGdF $4: 20 \% \mathrm{Yb}_{1} 1 \% \mathrm{Tm}_{1}, 29 \% \mathrm{Y} @ \mathrm{NaYF}_{4}$ (with $\mathrm{Gd}^{3+}$ ) and $\mathrm{NaYF}_{4}: 20 \% \mathrm{Yb}, 1 \% \mathrm{Tm} @ \mathrm{NaYF}_{4}$ (without $\mathrm{Gd}^{3+}$ ) by pulsed $980 \mathrm{~nm}$ excitation.

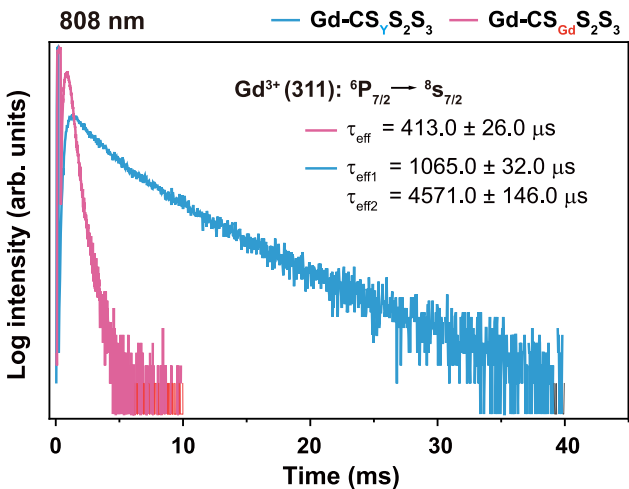

Fig. 5 Lifetime decay analysis. Upconversion luminescence decay curves of $\mathrm{Gd}^{3+}$ emissions at $311 \mathrm{~nm}$ from $\mathrm{Gd}-\mathrm{CS}_{\mathrm{Y}} \mathrm{S}_{2} \mathrm{~S}_{3}$ v.s. $\mathrm{Gd}-\mathrm{CS}_{\mathrm{Gd}} \mathrm{S}_{2} \mathrm{~S}_{3}$ by pulsed $808 \mathrm{~nm}$ excitation.

mechanism favors the upconversion emissions from high-lying energy levels.

To further verify the role of $\mathrm{NaYF}_{4}$ layer in enhancing the UVB and UVC emissions, we synthesized a group of Gd$\mathrm{CS}_{\mathrm{Y}} \mathrm{S}_{2} \mathrm{~S}_{3}, \mathrm{NaGdF}_{4}: 49 \% \mathrm{Yb}, 1 \% \mathrm{Tm}_{0} @ \mathrm{NaGdF}_{4}: 20 \% \mathrm{Yb} @ \mathrm{NaYF}_{4}: 10 \%$ $\mathrm{Yb}, 50 \% \mathrm{Nd} @ \mathrm{NaGdF}_{4}\left(\mathrm{Gd}-\mathrm{CS}_{1} \mathrm{~S}_{\mathrm{Y}} \mathrm{S}_{3}\right)$ and $\mathrm{NaGdF}_{4}: 49 \% \mathrm{Yb}, 1 \%$ $\mathrm{Tm} @ \mathrm{NaGdF}_{4}: 20 \% \mathrm{Yb} @ \mathrm{NaGdF}_{4}: 10 \% \mathrm{Yb}, 50 \% \mathrm{Nd} @ \mathrm{NaYF}_{4} \quad(\mathrm{Gd}-$ $\mathrm{CS}_{1} \mathrm{~S}_{2} \mathrm{~S}_{\mathrm{Y}}$ ) heterogeneous nanoparticles, in which $\mathrm{NaGdF}_{4}$ was selectively replaced by $\mathrm{NaYF}_{4}$ host lattice in the first, second and third layer, respectively (Fig. 6a). The intense UVB and UVC emission was only observed in Gd-CS $\mathrm{CS}_{2} \mathrm{~S}_{3}$ nanoparticles. The emission profiles of Gd-CS $\mathrm{S}_{\mathrm{Y}} \mathrm{S}_{3}$ and $\mathrm{Gd}-\mathrm{CS}_{1} \mathrm{~S}_{2} \mathrm{~S}_{\mathrm{Y}}$ were quite similar to $\mathrm{Gd}-\mathrm{CS}_{\mathrm{Gd}} \mathrm{S}_{2} \mathrm{~S}_{3}$ nanoparticles. Moreover, when the half of optically inert $\mathrm{Y}^{3+}$ ions in the first layer were replaced by the $\mathrm{Gd}^{3+}$ ions, a drastic reduction of the $\mathrm{Gd}^{3+}$ emission was observed, indicating that the $\mathrm{NaYF}_{4}$ with $\mathrm{Yb}^{3+}$ doping layer can effectively prevent the $\mathrm{Gd}^{3+}$ energy leakage (Supplementary Fig. 18).

We further prepared a group of Gd- $\mathrm{CS}_{\mathrm{Y}} \mathrm{S}_{2} \mathrm{~S}_{3}$ nanoparticles doped with $\mathrm{Tb}^{3+}$ or $\mathrm{Eu}^{3+}$ ions in the first layer $\mathrm{NaGdF}_{4}: 49 \% \mathrm{Yb}, 1 \%$ Tm@NaYF $: 20 \% \mathrm{Yb}, 15 \% \mathrm{~Tb}_{4} \mathrm{NaGdF}_{4}: 10 \% \mathrm{Yb}, 50 \% \mathrm{Nd} @ \mathrm{NaGdF}_{4}$

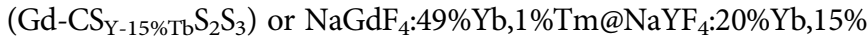

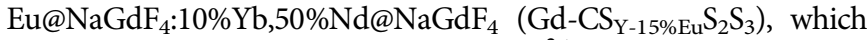
can extract the excitation energy from $\mathrm{Gd}^{3+}$ to emit green and red upconversion emissions through the scheme of energy migration upconversion (EMU) ${ }^{22}$. Upon excitation at $808 \mathrm{~nm}$, the characteristic emissions of $\mathrm{Tb}^{3+}$ and $\mathrm{Eu}^{3+}$ (highlighted in color) were observed (Fig. 6b, c and Supplementary Fig. 19), but no enhancement of UVB emissions observed. Doping with 15\% $\mathrm{Tb}^{3+}$ or $\mathrm{Eu}^{3+}$ in the outmost layer only led to weak emission of $\mathrm{Tb}^{3+}$ or $\mathrm{Eu}^{3+}$ (Supplementary Fig. 20). The weak $\mathrm{Tb}^{3+}$ and $\mathrm{Eu}^{3+}$ emissions were attributed to the interior energy trapping of the excitation energy in the $\mathrm{Gd}^{3+}$ sublattice. Together, these results indicate that an efficient energy transfer pathway $\left(\mathrm{Nd}^{3+} \rightarrow\right.$ $\mathrm{Yb}^{3+} \rightarrow \mathrm{Tm}^{3+} \rightarrow \mathrm{Gd}^{3+}$ ) occurs ${ }^{50}$, and the excitation energy of $\mathrm{Gd}^{3+}$ can be easily dissipated through the emission of $\mathrm{Tb}^{3+}$, $\mathrm{Eu}^{3+}$, or interior traps if without the first-shell layer of $20 \% \mathrm{Yb}^{3+}$ doped $\mathrm{NaYF}_{4}$.

Determination of the interior traps and $\mathrm{Gd}^{3+}$ energy recycling above ${ }^{6} \mathbf{P}_{\mathrm{J}}$. The interior energy flux leakage pathway through lattice vibration and multiphonon transitions can be neglected because of the large energy gap of about $32000 \mathrm{~cm}^{-1}$ of $\mathrm{Gd}^{3+}$ compared with the intrinsic low phonon energy of host materials $\left(\sim 350 \mathrm{~cm}^{-1}\right)^{47}$. Besides, it was reported that an efficient energy transfer can occur between $\mathrm{Gd}^{3+}$ and $\mathrm{Nd}^{3+}$ ions ${ }^{51}$. However, in our design, the energy transfer between these two ions did not happen. To preclude the possibility of the interior $\mathrm{Nd}^{3+}$ energy trapping, we prepared a pair of Gd-CS $\mathrm{Gd}_{2} \mathrm{~S}_{2}$ nanoparticles with and without $\mathrm{Nd}^{3+}$ dopant $\mathrm{NaGdF}_{4}: 49 \% \mathrm{Yb}, 1 \% \mathrm{Tm} @ \mathrm{NaGdF}_{4}: 20 \%$ $\mathrm{Yb} @ \mathrm{NaGdF}_{4}: 10 \% \mathrm{Yb}, 50 \% \mathrm{Nd} @ \mathrm{NaGdF}_{4}$ and $\mathrm{NaGdF}_{4}: 49 \% \mathrm{Yb}, 1 \%$ $\mathrm{Tm} @ \mathrm{NaGdF}_{4}: 20 \% \mathrm{Yb} @ \mathrm{NaGdF}_{4}: 10 \% \mathrm{Yb}, 0 \% \mathrm{Nd} @ \mathrm{NaGdF}_{4} \quad(\mathrm{Gd}-$ $\mathrm{CS}_{\mathrm{Gd}} \mathrm{S}_{50 \% \mathrm{Nd}} \mathrm{S}_{3}$ and $\left.\mathrm{Gd}-\mathrm{CS}_{\mathrm{Gd}} \mathrm{S}_{0 \% \mathrm{Nd}} \mathrm{S}_{3}\right)$. The lifetimes of $\mathrm{Gd}^{3+}$ $\left({ }^{6} \mathrm{D}_{\mathrm{J}},{ }^{6} \mathrm{I}_{\mathrm{J}},{ }^{6} \mathrm{P}_{\mathrm{J}}\right)$ and $\mathrm{Tm}^{3+}\left({ }^{1} \mathrm{I}_{6},{ }^{1} \mathrm{D}_{2}\right)$ were virtually unchanged after removing $\mathrm{Nd}^{3+}$ dopants in nanoparticles (Fig. 7a and Supplementary Fig. 21).

Since the $\mathrm{Gd}^{3+}-\mathrm{Gd}^{3+}$ energy migration is efficient and it can travel long distances ${ }^{22}$, it is reasonable to assume that the excitation energy may be quenched by the interior lattice defects in the heterogenous structure with multi-layers of the shell. In our design, $\mathrm{NaYF}_{4}$ in the first layer, effectively blocks the energy transfer from $\mathrm{Gd}^{3+}$ to interior lattice defects in the outer shell layers, resulting in the migrating energy only recycling within the core domain of $\mathrm{NaGdF}_{4}: \mathrm{Yb}, \mathrm{Tm}$ (Fig. $7 \mathrm{~b}$ ). To validate our hypothesis, we investigated the lifetimes of $\mathrm{Gd}-\mathrm{CS}_{\mathrm{Y}} \mathrm{S}_{2} \mathrm{~S}_{3}, \mathrm{Gd}-$ $\mathrm{CS}_{1} \mathrm{~S}_{\mathrm{Y}} \mathrm{S}_{3}$, and Gd-CS $\mathrm{S}_{2} \mathrm{~S}_{\mathrm{Y}}$ nanoparticles by changing the position of the $\mathrm{NaYF}_{4}$ layer. As shown in Fig. $7 \mathrm{c}$, the lifetime $\left(\mathrm{Gd}^{3+}\right.$ : $311 \mathrm{~nm}$ ) in Gd- $-\mathrm{CS}_{\mathrm{Y}} \mathrm{S}_{2} \mathrm{~S}_{3}$ is significantly longer than those in both 

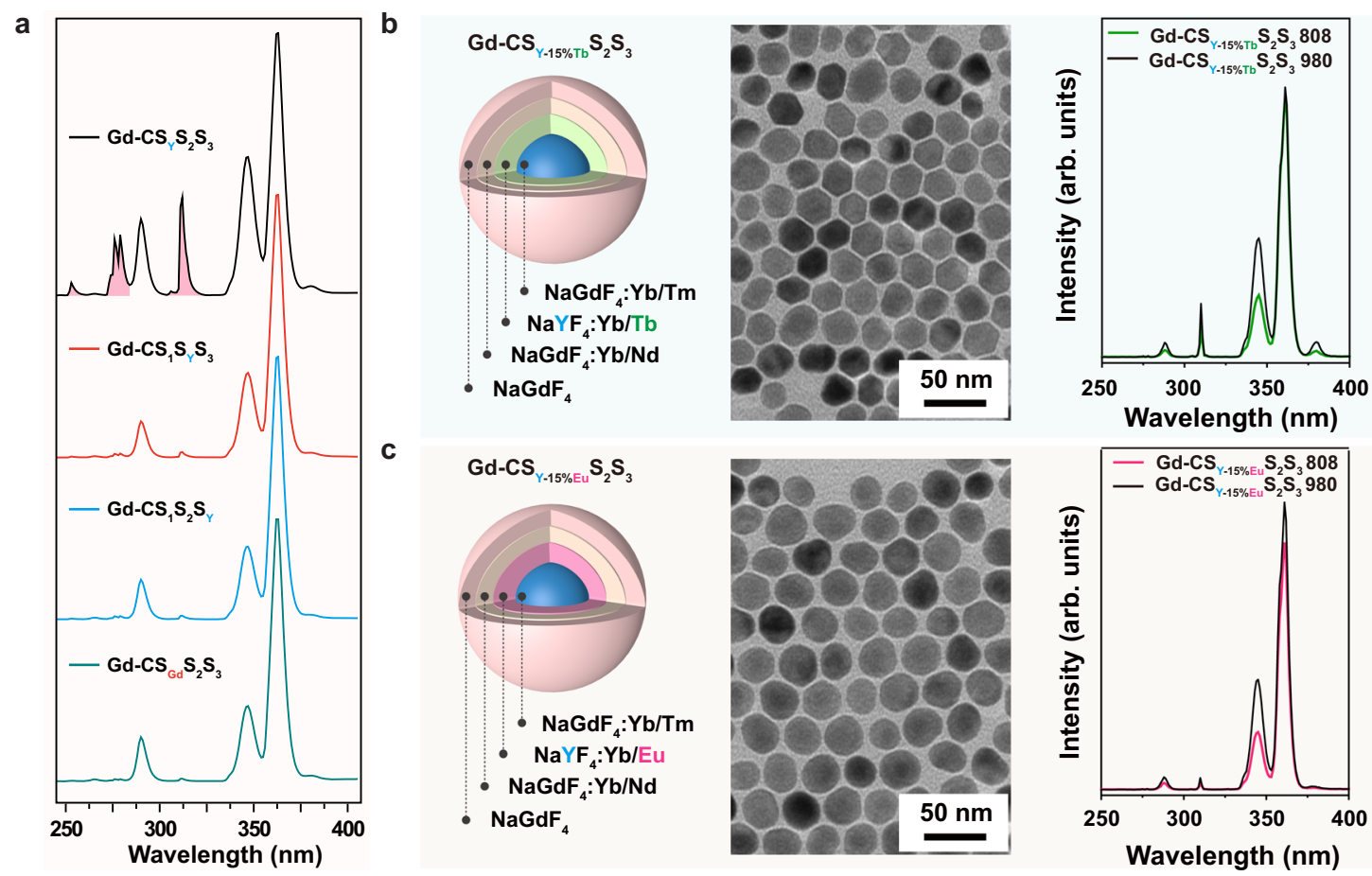

Fig. 6 Characterization of core-multishell nanoparticles with alternative dopants and structural layouts. a Room-temperature upconversion emission spectra of solutions containing $\mathrm{Gd}-\mathrm{CS}_{\mathrm{Y}} \mathrm{S}_{2} \mathrm{~S}_{3}, \mathrm{Gd}-\mathrm{CS}_{1} \mathrm{~S}_{\mathrm{Y}} \mathrm{S}_{3}, \mathrm{Gd}-\mathrm{CS}_{1} \mathrm{~S}_{2} \mathrm{~S}_{\mathrm{Y}}$, and $\mathrm{Gd}-\mathrm{CS}_{\mathrm{Gd}} \mathrm{S}_{2} \mathrm{~S}_{3}$ nanoparticles under $808 \mathrm{~nm}$ excitation at a power density of $10 \mathrm{~W} \mathrm{~cm}^{-2}$. b, c Schematic illustration, TEM images and photoluminescence spectra of the as-synthesized $\mathrm{Gd}_{-}-\mathrm{CS}_{\mathrm{Y}-15 \% \mathrm{~Tb}} \mathrm{~S}_{2} \mathrm{~S}_{3}$ and $\mathrm{Gd}_{-} \mathrm{CS}_{\mathrm{Y}-15 \%}$ $\mathrm{Eu}_{2} \mathrm{~S}_{3}$ nanoparticles.

Gd- $-\mathrm{CS}_{1} \mathrm{~S}_{\mathrm{Y}} \mathrm{S}_{3}$ and $\mathrm{Gd}-\mathrm{CS}_{1} \mathrm{~S}_{2} \mathrm{~S}_{\mathrm{Y}}$ nanoparticles. The prolonged lifetime of $\mathrm{Gd}^{3+}$ in $\mathrm{Gd}-\mathrm{CS}_{\mathrm{Y}} \mathrm{S}_{2} \mathrm{~S}_{3}$ nanoparticles is ascribed to the suppressed trapping of $\mathrm{Gd}^{3+}$ energy by interior lattice defects in the multi-shell regions. By contrast, a similar level of short lifetimes of $\mathrm{Gd}^{3+}$ in Gd-CS $\mathrm{Gd}_{2} \mathrm{~S}_{2} \mathrm{~S}_{3}$, Gd-CS $\mathrm{S}_{\mathrm{Y}} \mathrm{S}_{3}$, and $\mathrm{Gd}-\mathrm{CS}_{1} \mathrm{~S}_{2} \mathrm{~S}_{\mathrm{Y}}$ was observed, indicating that surface quenching was not responsible for the weak UV upconversion in conventional nanoparticles (Fig. 7d). This result is also consistent with our luminescence analysis in that a significantly stronger UV luminescence of Gd-CS $\mathrm{C}_{\mathrm{Y}} \mathrm{S}_{2} \mathrm{~S}_{3}$ nanoparticles compared with those of Gd-CS $\mathrm{Gd}_{2} \mathrm{~S}_{2} \mathrm{~S}_{3}, \mathrm{Gd}-\mathrm{CS}_{1} \mathrm{~S}_{\mathrm{Y}} \mathrm{S}_{3}$, and $\mathrm{Gd}-\mathrm{CS}_{1} \mathrm{~S}_{2} \mathrm{~S}_{\mathrm{Y}}$ counterparts.

Furthermore, a $\mathrm{Gd}^{3+}$ content of $50 \mathrm{~mol} \%$ produced an optimum energy-migration property with a $\mathrm{Gd}^{3+}-\mathrm{Gd}^{3+}$ separation of $5.32 \AA$, which can be approximately calculated using the Eq. $3:^{52}$

$$
d=\left(\frac{a^{2} c \sqrt{3} / 2}{1.5 x}\right)^{1 / 3}
$$

For the hexagonal $\mathrm{NaGdF}_{4}$ unit cell, $a=6.02 \AA, c=3.60 \AA$. The short distance between $\mathrm{Gd}^{3+}$ ions indicates that the $\mathrm{Gd}^{3+}$ $-\mathrm{Gd}^{3+}$ energy migration is dominated by exchange interaction ${ }^{46}$. Moreover, it was reported by the Blasse group, $P_{\mathrm{em}}$ for $\mathrm{Gd}^{3+}$ is about $\left.5 \times 10^{2} \mathrm{~s}^{-1}, P_{(\mathrm{Gd}}{ }^{3+} \rightarrow \mathrm{Gd}^{3+}\right)$ is about $10^{7} \mathrm{~s}^{-1} . P_{\mathrm{em}}$ denotes the

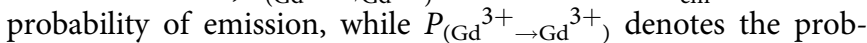
ability for energy migration ${ }^{46}$. These results indicate that the excitation energy can be transferred more than $10^{5}$ times for the excited $\mathrm{Gd}^{3+}$. After $\mathrm{NaGdF}_{4}$ was replaced with $\mathrm{NaYF}_{4}$ in the first layer, a significant increase in $\mathrm{Gd}^{3+}$ lifetime was observed (Fig. 7c), suggesting the probability of $\mathrm{Gd}^{3+}-\mathrm{Gd}^{3+}$ energy migration within the core domain was significantly increased. Taken these together, the results conclusively suggested that the $\mathrm{NaYF}_{4}$ shell can impede the fast migrating energy within the network of $\mathrm{Gd}^{3+}$ ions from being trapped by the interior lattice defects in the outer multi-layer shell, which promotes the occurrence of energy hopping in $\mathrm{Gd}^{3+}$ sublattice at the core domain of $\mathrm{NaGdF}_{4}: \mathrm{Yb}, \mathrm{Tm}$, thereby realizing the intense UVB and UVC upconversion emissions.

Enhancement in highly doped single nanoparticles. To further evaluate UCEL mode in enhancing the high-order upconversion emissions in the heterogenous core-multishell structures, we implemented the similar design in the highly doped UCNP core, e.g., $\mathrm{NaGdF}_{4}: 49 \% \mathrm{Yb}, 8 \% \mathrm{Tm}_{\mathrm{N}} @ \mathrm{NaYF}_{4}: 20 \% \mathrm{Yb} @ \mathrm{NaGdF}_{4}: 10 \%$ $\mathrm{Yb}, 50 \% \mathrm{Nd} @ \mathrm{NaYF}_{4}$ and $\mathrm{NaGdF}_{4}: 49 \% \mathrm{Yb}, 8 \% \mathrm{Tm} @ \mathrm{NaGdF}_{4}: 20 \%$ $\mathrm{Yb} @ \mathrm{NaGdF}_{4}: 10 \% \quad \mathrm{Yb}, 50 \% \mathrm{Nd} @ \mathrm{NaGdF}_{4} \quad\left(\mathrm{Gd}-\mathrm{C}_{8} \% \mathrm{Tm}_{\mathrm{Y}} \mathrm{S}_{2} \mathrm{~S}_{3}\right.$ and Gd- $\mathrm{C}_{8 \% \mathrm{Tm}} \mathrm{S}_{\mathrm{Gd}} \mathrm{S}_{2} \mathrm{~S}_{3}$ ), and quantify the brightness of single UCNPs using a purpose-built confocal microscopy system (Supplementary Fig. 22). Due to the significant UV absorption by the optical components, including the objective lens and mirrors, instead of a direct quantification of the UVC emissions at a single nanoparticle level, we monitored the amount of the blue band emissions from a single nanoparticle. Under the same excitation power from both $808 \mathrm{~nm}$ and $\sim 980 \mathrm{~nm}$ lasers, the emission intensities of $\mathrm{Gd}-\mathrm{C}_{1} \% \mathrm{Tm} \mathrm{S}_{\mathrm{Y}} \mathrm{S}_{2} \mathrm{~S}_{3}$ and $\mathrm{Gd}-\mathrm{C}_{1 \% \mathrm{Tm}} \mathrm{S}_{\mathrm{Gd}} \mathrm{S}_{2} \mathrm{~S}_{3}$ nanoparticles under the $808 \mathrm{~nm}$ excitation were $\sim 4$ times and $\sim 5$ times higher than those under the $\sim 980 \mathrm{~nm}$ excitation, respectively (Supplementary Fig. 23). In contrast, much higher enhancement factors of the highly doped $\mathrm{Gd}-\mathrm{C}_{8} \% \mathrm{Tm}_{\mathrm{Y}} \mathrm{S}_{\mathrm{Y}} \mathrm{S}_{2} \mathrm{~S}_{3}$ ( $\sim 25$ times) and Gd- $\mathrm{C}_{8 \% \mathrm{Tm}} \mathrm{S}_{\mathrm{Gd}} \mathrm{S}_{2} \mathrm{~S}_{3}$ ( $\sim 15$ times) nanoparticles were achieved under the $808 \mathrm{~nm}$ v.s. $\sim 980 \mathrm{~nm}$ excitations. These results suggest UCEL mode could be broadly applied to a variety of UCNP core concentrations ${ }^{38}$ and under a large dynamic range of excitation power densities ${ }^{53}$, suitable for both ensemble and single nanoparticle applications ${ }^{54}$.

Potential in enhancing Reactive Oxygen Species (ROS) generation. Moreover, we prepared the titanium dioxide $\left(\mathrm{TiO}_{2}\right)$ coated UCNPs in which $\mathrm{TiO}_{2}$ serves as the photosensitizer'55. 
a

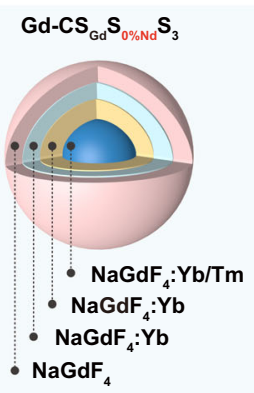

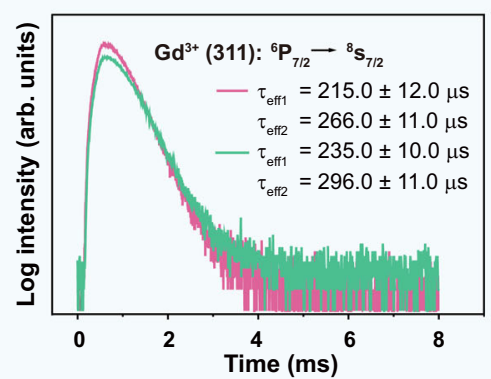

$-\mathrm{Gd}_{-} \mathbf{C S}_{\mathrm{Gd}} \mathbf{S}_{50 \% \mathrm{Nd}} \mathbf{S}_{3} \quad-\mathrm{Gd}-\mathrm{CS}_{\mathrm{Gd}} \mathbf{S}_{0 \% \mathrm{Nd}} \mathbf{S}_{3}$

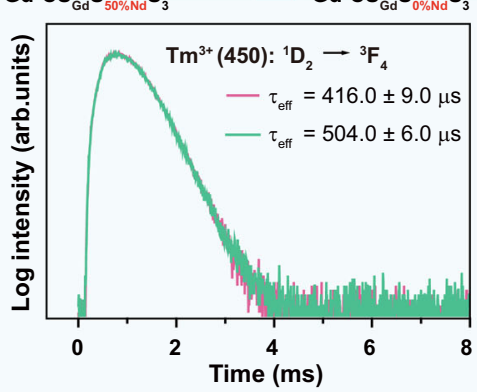

b

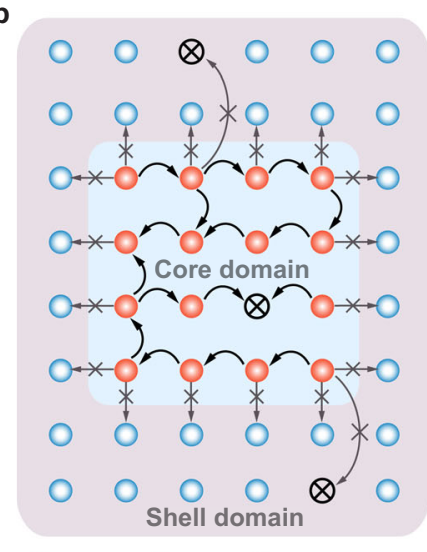

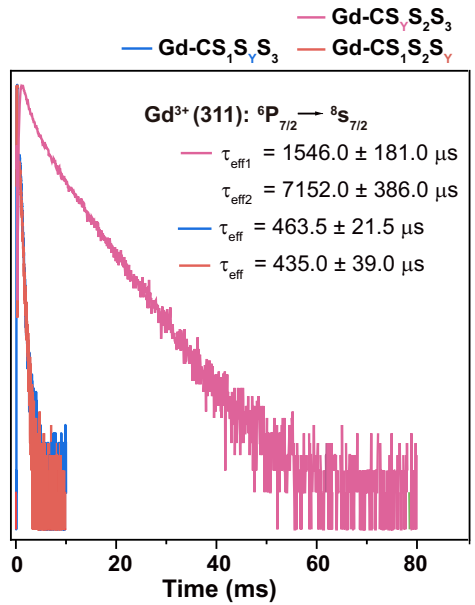

d

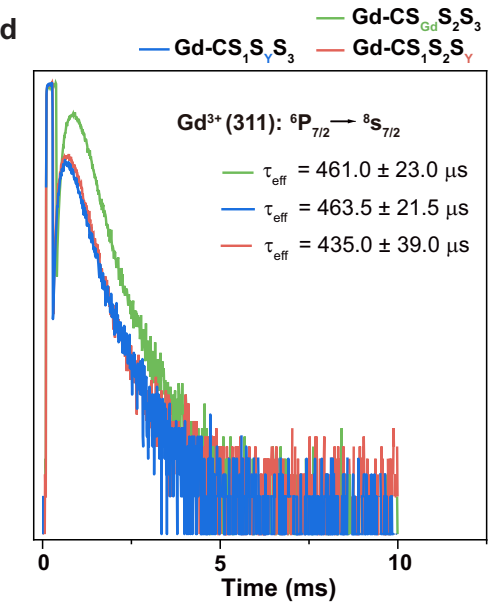

Fig. 7 Mechanistic investigation of $\mathbf{G d}^{\mathbf{3}+}$ energy recycling to avoid the interior traps in the heterogeneous core-shell nanoparticle. a Schematic illustration of the as-synthesized $\mathrm{Gd}-\mathrm{CS}_{\mathrm{Gd}} \mathrm{S}_{0 \% \mathrm{Nd}} \mathrm{S}_{3}$ nanoparticles, and the upconversion luminescence decay curves of $\mathrm{Gd}^{3+} \mathrm{emission}$ at $311 \mathrm{~nm}$ and $\mathrm{Tm}^{3+}$ emission at $450 \mathrm{~nm}$ of $\mathrm{Gd}-\mathrm{CS}_{\mathrm{Gd}} \mathrm{S}_{50 \% \mathrm{Nd}} \mathrm{S}_{3}$ and $\mathrm{Gd}_{-}-\mathrm{CS}_{\mathrm{Gd}} \mathrm{S}_{0 \% \mathrm{Nd}} \mathrm{S}_{3}$ nanoparticles under $980 \mathrm{~nm}$ excitation, respectively. b Schematic illustration of energy recycling in $\mathrm{Gd}^{3+}$ sublattice at the core domain of $\mathrm{NaGdF}_{4}: \mathrm{Yb}_{1} \mathrm{Tm}$. c The upconversion luminescence decay curves of $\mathrm{Gd}^{3+}$ emission at $311 \mathrm{~nm}$ in $\mathrm{Gd}-$ $\mathrm{CS}_{Y} \mathrm{~S}_{2} \mathrm{~S}_{3}, \mathrm{Gd}-\mathrm{CS}_{1} \mathrm{~S}_{Y} \mathrm{~S}_{3}$, and $\mathrm{Gd}-\mathrm{CS}_{1} \mathrm{~S}_{2} \mathrm{~S}_{\mathrm{Y}}$ nanoparticles by the pulsed $808 \mathrm{~nm}$ excitation. $\mathbf{d}$ The upconversion luminescence decay curves of $\mathrm{Gd}^{3+}$ emission at $311 \mathrm{~nm}$ in $\mathrm{Gd}-\mathrm{CS}_{\mathrm{Gd}} \mathrm{S}_{2} \mathrm{~S}_{3}, \mathrm{Gd}-\mathrm{CS}_{1} \mathrm{~S}_{Y} \mathrm{~S}_{3}$, and $\mathrm{Gd}-\mathrm{CS}_{1} \mathrm{~S}_{2} \mathrm{~S}_{\mathrm{Y}}$ nanoparticles by the pulsed $808 \mathrm{~nm}$ excitation.

TEM and X-ray powder diffraction (XRD) analysis confirmed the successful synthesis (Supplementary Fig. 24), and compositional analysis of these nanocomposites by energy-dispersive $\mathrm{X}$-ray spectroscopy (EDX) confirms the presence of $\mathrm{Ti}^{4+}, \mathrm{Nd}^{3+}, \mathrm{Gd}^{3+}$, $\mathrm{Yb}^{3+}$, and $\mathrm{Tm}^{3+}$ (Supplementary Fig. 25). As shown in Supplementary Fig. 26, the emission Gd-CS $\mathrm{S}_{2} \mathrm{~S}_{3} @ \mathrm{TiO}_{2}$ became weaker compared with Gd-CS $\mathrm{Y}_{\mathrm{Y}} \mathrm{S}_{3}$ nanoparticles due to the absorbance of UV emission by the $\mathrm{TiO}_{2}$ shell. The ability to generate singlet oxygen $\left({ }^{1} \mathrm{O}_{2}\right)$ of the as-synthesized nanocomposites was evaluated by the 1,3-diphenylisobenzofuran (DPBF) chemical probe under $808 \mathrm{~nm}$ laser irradiation. The characteristic absorbance of DPBF gradually decreased with the increase in irradiation time, the characteristic absorption decreased with time, indicating the successful generation of ${ }^{1} \mathrm{O}_{2}$ (Supplementary Fig. 26b). These results indicate the enticing prospects of NIR light-mediated photosensitizing nanocomposites for ROS generation and their potential applications in photocatalysis and biomedical fields.

\section{Discussion}

In this study, we demonstrated a UCEL approach through the core-multishell heterogeneous structure design to regulate the energy transfer pathway in lanthanide-doped UCNPs for UVC and UVB generation by $808 \mathrm{~nm}$ excitation. The key to this design is the utilization of an optical inert $\mathrm{NaYF}_{4}$ host lattice with $\mathrm{Yb}^{3+}$ doping as an interlayer between the multiple cascade NIR photon sensitization shells and upconversion emitting core. Therefore, the sensitized NIR excitation energies can be transferred inbound and upconverted at the core domain of $\mathrm{NaGdF}_{4}: \mathrm{Yb}$, Tm, where high-concentration $\mathrm{Gd}^{3+}$ ions can recycle among the higherlying excited energy states above ${ }^{6} \mathrm{P}_{\mathrm{J}}$ to realize intense UVB and UVC upconversion emissions. We believe this approach will advance the design rationale for enhancing the NIR sensitized UV upconversion emissions towards the potential areas of biomedicine, information technology, photocatalysis, environmental science, and many other emerging fields.

\section{Methods}

Nanoparticles synthesis. We synthesized the core-multishell nanoparticles using the method described in ref. ${ }^{24}$. and ref. ${ }^{40}$. Additional experimental details are provided in the Supplementary Note.

Synthesis of UCNPs@TiO ${ }_{2}$ nanocomposites. Gd- $\mathrm{CS}_{\mathrm{Y}} \mathrm{S}_{2} \mathrm{~S}_{3} @ \mathrm{TiO}_{2}$ nanocomposites were synthesized according to a modified literature procedure ${ }^{55,56}$. Typically, $66 \mathrm{mg} / \mathrm{mL}(0.3 \mathrm{~mL})$ as-prepared oleic acid nanoparticles $\mathrm{Gd}-\mathrm{CS}_{\mathrm{Y}} \mathrm{S}_{2} \mathrm{~S}_{3}$ were dispersed in a $0.2 \mathrm{M} \mathrm{HCl}$ solution followed by ultrasonication to remove the surface ligands. After that, ligand-free UCNPs were collected via centrifugation. The ligand-free nanoparticles were washed with deionized water and ethanol several times, and then dispersed in $4 \mathrm{~mL}$ of deionized water containing $0.8 \mathrm{~g}$ polyvinylpyrolidone (average Mw 40000 ) with ultrasonication and stirring for $1 \mathrm{~h}$. Then, $20 \mathrm{~mL}$ ethanol was added under magnetic stirring for $30 \mathrm{~min}$. $\mathrm{TiF}_{4}$ aqueous solution $(2.4 \mathrm{~mL} 0.025 \mathrm{M})$ was dropwise added into the solution under stirring. Then the whole solution was transferred into a $50 \mathrm{~mL}$ Teflon-lines autoclave and heated at $180^{\circ} \mathrm{C}$ for $4 \mathrm{~h}$. After cooling to the room temperature, the as-prepared products were collected by centrifugation, washed with deionized water and ethanol several times, and dried at $65^{\circ} \mathrm{C}$

Single particle imaging. The emission intensities of single nanoparticles were recorded using a laboratory-built confocal microscopy system. Supplementary Fig. 25 shows the schematic drawing of the experimental setup, where UCNPs are excited by a polarization-maintaining single-mode fiber-coupled $\sim 980 \mathrm{~nm}$ 
(BL976-PAG900, controller CLD1015, Thorlabs) or 808 nm (F280APC-808, Leoptics) diode lasers. The first half-wave plate (HWP, WPH05M-980, Thorlabs) and a polarized beam splitter (PBS, CCM1-PBS252/M, Thorlabs) are employed to control the excitation power by rotating HWP electronically. The purpose of the second HWP is to turn the polarization from horizontal to vertical. The same setup is used for the $808 \mathrm{~nm}$ laser excitation, combined to the $\sim 980 \mathrm{~nm}$ excitation path by the first dichroic mirror (DM, T842lp, Chroma). After collimation, the excitation beam is reflected by the short-pass dichroic mirror (DM, T785spxrxt-UF1, Chroma), and focused through a high numerical aperture objective (UPlanSApo, $100 \times / 1.40$ oil, Olympus) to the sample slide. Photoluminescence is collected by the same objective and split from the excitation beams by a dichroic mirror DM. The emission signals are filtered by a short pass filter (SPF, FF01-750SP, Semrock), coupled into a multimode fiber (MMF, M42L02, Thorlabs), and detected by a single-photon counting avalanche photodiode (SPAD, SPCM-AQRH-14-FC, Excelitas). The MMF can also be switched to a monochromator (iHR550, Horiba) for upconversion emission spectrum measurement.

Evaluation of singlet oxygen generation. The chemical probe 1,3-diphenylisobenzofuran (DPBF) can be used to evaluate the amount of produced singlet oxygen $\left({ }^{1} \mathrm{O}_{2}\right)$ from the as-prepared $\mathrm{Gd}-\mathrm{CS}_{\mathrm{Y}} \mathrm{S}_{2} \mathrm{~S}_{3} @ \mathrm{TiO}_{2}$ under $808 \mathrm{~nm}$ laser irradiation. DPBF can react with singlet oxygen $\left({ }^{1} \mathrm{O}_{2}\right)$ irreversibly and then cause the intensity decrease of its characteristic absorption at $417 \mathrm{~nm}^{55}$. Therefore, the amount of ${ }^{1} \mathrm{O}_{2}$ produced under laser irradiation can be evaluated by the absorption signal of DPBF with a UV-Vis absorption spectrum.

Caculation of absorption cross-section $\boldsymbol{\sigma}$ of $\mathbf{N d}^{\mathbf{3}+}$. The approximate absorption cross-section $\sigma$ of $\mathrm{Nd}^{3+}$ at $808 \mathrm{~nm}$ was calculated from the $\mathrm{UV}-\mathrm{Vis}$ absorption spectra of the nanoparticles using the following equations ${ }^{44}$ :

$$
\begin{gathered}
A=\varepsilon \cdot M \cdot l \\
\sigma=\frac{\varepsilon}{n}
\end{gathered}
$$

where $A$ is the absorbance, $\varepsilon$ is the absorption coefficient, $M$ is the molar concentration of $\mathrm{Nd}^{3+}, l$ is the path length, $n$ is the atomic number density of $\mathrm{Nd}^{3+}$ ions. $\sigma=1.5 \times 10^{-19} \mathrm{~cm}^{2}\left(808 \mathrm{~nm}\right.$ for Gd-CS $\left.S_{2} S_{3}\right), \sigma=1.3 \times 10^{-19} \mathrm{~cm}^{2}(808 \mathrm{~nm}$ for $\mathrm{Gd}-\mathrm{CS}_{\mathrm{Gd}} \mathrm{S}_{2} \mathrm{~S}_{3}$ ).

\section{Data availability}

All the relevant data are available from the correspondence authors upon reasonable request. Source data are provided with this paper.

Received: 5 October 2020; Accepted: 21 June 2021;

Published online: 16 July 2021

\section{References}

1. Auzel, F. Upconversion and anti-stokes processes with $\mathrm{f}$ and $\mathrm{d}$ ions in solids. Chem. Rev. 104, 139-174 (2004).

2. Bünzli, J.-C. G. \& Piguet, C. Taking advantage of luminescent lanthanide ions. Chem. Soc. Rev. 34, 1048-1077 (2005).

3. Dong, H., Sun, L. D. \& Yan, C. H. Energy transfer in lanthanide upconversion studies for extended optical applications. Chem. Soc. Rev. 44, 1608-1634 (2015).

4. Wen, S. et al. Future and challenges for hybrid upconversion nanosystems. Nat. Photonics 12, 828-838 (2019).

5. Bettinelli, M., Carlos, L. D. \& Liu, X. Lanthanide-doped upconversion nanoparticles. Phys. Today 68, 38-44 (2015).

6. Su, Q., Feng, W., Yang, D. \& Li, F. Resonance energy transfer in upconversion nanoplatforms for selective biodetection. Acc. Chem. Res. 50, 32-40 (2017)

7. Jalani, G. et al. Photocleavable hydrogel-coated upconverting nanoparticles: a multifunctional theranostic platform for NIR imaging and on-demand macromolecular delivery. J. Am. Chem. Soc. 138, 1078-1083 (2016).

8. Yao, C. et al. Near-infrared-triggered azobenzene-liposome/upconversion nanoparticle hybrid vesicles for remotely controlled drug delivery to overcome cancer multidrug resistance. Adv. Mater. 28, 9341-9348 (2016)

9. Zhang, Z. et al. Upconversion superballs for programmable photoactivation of therapeutics. Nat. Commun. 10, 4586 (2019).

10. Gao, W., Zhang, W. \& Lu, G. A two-pronged strategy to enhance visible-lightdriven overall water splitting via visible-to-ultraviolet upconversion coupling with hydrogen-oxygen recombination inhibition. Appl. Catal. B-Environ. 212, 23-31 (2017).

11. Anwer, H. \& Park, J. W. Near-infrared to visible photon transition by upconverting $\mathrm{NaYF}_{4}: \mathrm{Yb}^{3+}, \mathrm{Gd}^{3+}, \mathrm{Tm}^{3+} @ \mathrm{Bi}_{2} \mathrm{WO}_{6}$ core@shell composite for bisphenol a degradation in solar light. Appl. Catal. B-Environ. 243, 438-447 (2019).

12. Chen, $\mathrm{X}$. et al. Confining energy migration in upconversion nanoparticles towards deep ultraviolet lasing. Nat. Commun. 7, 10304 (2016).

13. Zheng, K. et al. Rewritable optical memory through high-registry orthogonal upconversion. Adv. Mater. 30, 1801726 (2018).

14. Bansal, A. \& Zhang, Y. Photocontrolled nanoparticle delivery systems for biomedical applications. Acc. Chem. Res. 47, 3052-3060 (2014).

15. Jayakumar, M. K. G., Idris, N. M. \& Zhang, Y. Remote activation of biomolecules in deep tissues using near-infrared-to-UV upconversion nanotransducers. Proc. Natl Acad. Sci. USA 109, 8483-8488 (2012).

16. Dai, Y. et al. In vivo multimodality imaging and cancer therapy by nearinfrared light-triggered trans-platinum pro-drug-conjugated upconversion nanoparticles. J. Am. Chem. Soc. 135, 18920-18929 (2013).

17. Zhao, J., Chu, H., Zhao, Y., Lu, Y. \& Li, L. A NIR light gated DNA nanodevice for spatiotemporally controlled imaging of microRNA in cells and animals. J. Am. Chem. Soc. 141, 7056-7062 (2019).

18. Shi, F., Wang, J., Zhang, D., Qin, G. \& Qin, W. Greatly enhanced size-tunable ultraviolet upconversion luminescence of monodisperse $\beta-\mathrm{NaYF}_{4}: \mathrm{Yb}, \mathrm{Tm}$ nanocrystals. J. Mater. Chem. 21, 13413-13421 (2011).

19. Dawson, P. \& Romanowsk, M. Excitation modulation of upconversion nanoparticles for switch-like control of ultraviolet luminescence. J. Am. Chem. Soc. 140, 5714-5718 (2018).

20. Zhao, C. et al. $\mathrm{Li}^{+}$ion doping: an approach for improving the crystallinity and upconversion emissions of $\mathrm{NaYF}_{4}: \mathrm{Yb}^{3+}, \mathrm{Tm}^{3+}$ nanoparticles. Nanoscale $\mathbf{5}$, 8084-8089 (2013)

21. Wang, F., Wang, J. \& Liu, X. Direct evidence of a surface quenching effect on size-dependent luminescence of upconversion nanoparticles. Angew. Chem. Int. Ed. 49, 7456-7460 (2010).

22. Wang, F. et al. Tuning upconversion through energy migration in core-shell nanoparticles. Nat. Mater. 10, 968-973 (2011).

23. Sun, T. et al. Integrating temporal and spatial control of electronic transitions for bright multiphoton upconversion. Nat. Commun. 10, 1811 (2019).

24. Su, Q. et al. The effect of surface coating on energy migration-mediated upconversion. J. Am. Chem. Soc. 134, 20849-20857 (2012).

25. Chen, Q. et al. Confining excitation energy in $\mathrm{Er}^{3+}$-sensitized upconversion nanocrystals through $\mathrm{Tm}^{3+}$-mediated transient energy trapping. Angew. Chem. Int. Ed. 56, 7605-7609 (2017).

26. Wang, Y. et al. $\mathrm{Nd}^{3+}$-sensitized upconversion nanophosphors: efficient in vivo bioimaging probes with minimized heating effect. ACS Nano 7, 7200-7206 (2013)

27. Wang, H., Li, Y., Yang, M., Wang, P. \& Gu, Y. FRET-based upconversion nanoprobe sensitized by $\mathrm{Nd}^{3+}$ for the ratiometric detection of hydrogen peroxide in vivo. ACS Appl. Mater. Interfaces 11, 7441-7449 (2019).

28. Xu, J. et al. Highly emissive dye-sensitized upconversion nanostructure for dual-photosensitizer photodynamic therapy and bioimaging. ACS Nano 11, 4133-4144 (2017).

29. Zuo, J. et al. Near infrared light sensitive ultraviolet-blue nanophotoswitch for imaging-guided "off-on" therapy. ACS Nano 12, 3217-3225 (2018).

30. Chan, M.-H. et al. Nanobubble-embedded inorganic $808 \mathrm{~nm}$ excited upconversion nanocomposites for tumor multiple imaging and treatment. Chem. Sci. 9, 3141-3151 (2018).

31. Liu, C. et al. sensitized upconversion metal-organic $\mathrm{Nd}^{3+}{ }^{-}$frameworks for mitochondria-targeted amplified photodynamic therapy. Angew. Chem. Int. Ed. 59, 2634-Nd32638 (2020).

32. Zhang, Y. et al. Ultrasmall-superbright neodymium upconversion nanoparticles via energy migration manipulation and lattice modification: 808 nm-activated drug release. ACS Nano 11, 2846-2857 (2017).

33. Tan, L. et al. Preparation of multishell-structured $\mathrm{NaYF}_{4}: \mathrm{Yb}, \mathrm{Tm}, \mathrm{Nd} @ \mathrm{NaYF}_{4}$ $\mathrm{Yb}, \mathrm{Nd} @ \mathrm{SiO}_{2} @ \mathrm{ZnO}$ nanospheres with effective NIR-induced photocatalytic activity. J. Phys. Chem. C. 124, 18081-18090 (2020).

34. Xie, X. et al. Mechanistic investigation of photon upconversion in $\mathrm{Nd}^{3}$ ${ }_{+}^{+}$-sensitized core-shell nanoparticles. J. Am. Chem. Soc. 135, 12608-12611 (2013).

35. Wen, H. et al. Upconverting near-infrared light through energy management in core-shell-shell nanoparticles. Angew. Chem. Int. Ed. 52, 13419-13423 (2013).

36. Shen, J. et al. Engineering the upconversion nanoparticle excitation wavelength: cascade sensitization of tri-doped upconversion colloidal nanoparticles at $800 \mathrm{~nm}$. Adv. Opt. Mater. 1, 644-650 (2013).

37. Zhong, Y. et al. Elimination of photon quenching by a transition layer to fabricate a quenching-shield sandwich structure for $800 \mathrm{~nm}$ excited upconversion luminescence of $\mathrm{Nd}^{3+}$-sensitized nanoparticles. Adv. Mater. 26, 2831-2837 (2014).

38. Wen, S. et al. Advances in highly doped upconversion nanoparticles. Nat. Commun. 9, 2415 (2018).

39. Liao, J., Jin, D., Chen, C., Li, Y. \& Zhou, J. Helix shape power-dependent properties of single upconversion nanoparticles. J. Phys. Chem. Lett. 11, $2883-2890(2020)$. 
40. Wang, S. et al. Comparative investigation of the optical spectroscopic and thermal effect in $\mathrm{Nd}^{3+}$-doped nanoparticles. Nanoscale 11, 10220-10228 (2019).

41. Qin, W. et al. Ultraviolet upconversion fluorescence from ${ }^{6} \mathrm{D}_{\mathrm{J}}$ of $\mathrm{Gd}^{3+}$ induced by $980 \mathrm{~nm}$ excitation. Opt. Lett. 33, 2167-2169 (2008).

42. Zheng, K., Qin, W., Cao, C., Zhao, D. \& Wang, L. NIR to VUV: seven-photon upconversion emissions from $\mathrm{Gd}^{3+}$ ions in fluoride nanocrystals. J. Phys. Chem. Lett. 6, 556-560 (2015)

43. Qin, W. et al. Multi-ion cooperative processes in $\mathrm{Yb}^{3+}$ clusters. Light Sci. Appl. 3, e193 (2014).

44. $\mathrm{Xu}, \mathrm{Y}$. et al. Crystal growth and optical properties of $\mathrm{YbAl}_{3}\left(\mathrm{BO}_{3}\right)_{4}$ : a promising stoichiometric laser crystal. J. Cryst. Growth 252, 241-245 (2003).

45. Pollnau, M., Gamelin, D. R., Lüthi, S. R., Güdel, H. U. \& Hehlen, M. P. Power dependence of upconversion luminescence in lanthanide and transitionmetal-ion systems. Phys. Rev. B 61, 3337-3346 (2000).

46. Blasse, G. The physics of new luminescent materials. Mater. Chem. Phys. 16, 201-236 (1987).

47. Blasse, G., Grabmaier, B. C. in Energy Transfer. Luminescent Materials Springer, (Springer, 1994).

48. Weber, M. J. Optical properties of $\mathrm{Yb}^{3+}$ and $\mathrm{Nd}^{3+}-\mathrm{Yb}^{3+}$ energy transfer in $\mathrm{YAlO}_{3}$. Phys. Rev. B 4, 3153-3159 (1971).

49. Bartosiewicz, K., Babin, V., Kamada, K., Yoshikawa, A. \& Nikl, M. Energy migration processes in undoped and Ce-doped multicomponent garnet single crystal scintillators. J. Lumin. 166, 177-122 (2015).

50. Pokhrel, M., Valdes, C. \& Mao, Y. Ultraviolet upconversion enhancement in triply doped $\mathrm{NaYF}_{4}: \mathrm{Tm}^{3+}, \mathrm{Yb}^{3+}$ particles: the role of $\mathrm{Nd}^{3+}$ or $\mathrm{Gd}^{3+}$ codoping. Opt. Mat. 58, 67e75 (2016).

51. Zhu, Q. et al. $\mathrm{Yb}^{3+}$-sensitized upconversion and downshifting luminescence in $\mathrm{Nd}^{3+}$ ions through energy migration. Dalton Trans. 47, 8581-8584 (2018).

52. Zhou, B. et al. NIR II-responsive photon upconversion through energy migration in an ytterbium sublattice. Nat. Photonics 14, 760-766 (2020).

53. Wang, F. et al. Microscopic inspection and tracking of single upconversion nanoparticles in living cells. Light Sci. Appl. 7, 18007 (2018).

54. Zhou, J., Chizhik, A. I., Chu, S. \& Jin, D. Single-particle spectroscopy for functional nanomaterials. Nature 579, 41-50 (2020).

55. Hou, Z. et al. UV-emitting upconversion-based $\mathrm{TiO}_{2}$ photosensitizing nanoplatform: near-infrared light mediated in vivo photodynamic therapy via mitochondria-involved apoptosis pathway. ACS Nano 9, 2584-2599 (2015).

56. Zhang, Y. \& Hong, Z. Synthesis of lanthanide-doped $\mathrm{NaYF}_{4} @ \mathrm{TiO}_{2}$ core-shell composites with highly crystalline and tunable $\mathrm{TiO}_{2}$ shells under mild conditions and their upconversionbased photocatalysis. Nanoscale $\mathbf{5}$, 8930-8933 (2013).

\section{Acknowledgements}

The authors thank the National Basic Research Program of China (No. 2016YFA0201600), the National Natural Science Foundation of China (Nos. 21701109 and 31771105), Shanghai Shuguang Program (18SG29) and Natural Science

Foundation of Shanghai (18ZR1401700) for financial supports. The authors acknowledge the assistance of SUSTech Core Research Facilities. The authors thank Prof. X. Liu, Prof. F. Li, Prof. F. Wang, Prof. K. Zheng, Prof. X. Zhu, Prof. A. Cao, Dr. S. Han and Dr. J. Zhou for helpful discussions. The authors thank Prof. W. Feng and Y. Cai for their help with lifetime measurements. The authors thank R. Liu for her help with quantum field measurements.

\section{Author contributions}

Q. S. and D. J. conceived the project. Q. S., H. W., and D. J. designed the experiments and supervised the research. Q. S., H. L. W., Y. L., C. C., M. G., S. W., Y. S., and Z. C. were primarily responsible for the experiments of nanoparticles synthesis and characterization. Q. S., D. J., H. L. W., Y. L., C. C., Y. S., and S. W. contributed to the data analyses and discussion. Q. S. and H. L. W. prepared the figures. Q. S. and D. J. wrote the paper with input from other authors.

\section{Competing interests}

The authors declare no competing interests.

\section{Additional information}

Supplementary information The online version contains supplementary material available at https://doi.org/10.1038/s41467-021-24664-x.

Correspondence and requests for materials should be addressed to Q.S., H.W. or D.J.

Peer review information Nature Communications thanks the anonymous reviewers for their contribution to the peer review of this work. Peer reviewer reports are available.

Reprints and permission information is available at http://www.nature.com/reprints

Publisher's note Springer Nature remains neutral with regard to jurisdictional claims in published maps and institutional affiliations.

Open Access This article is licensed under a Creative Commons Attribution 4.0 International License, which permits use, sharing, adaptation, distribution and reproduction in any medium or format, as long as you give appropriate credit to the original author(s) and the source, provide a link to the Creative Commons license, and indicate if changes were made. The images or other third party material in this article are included in the article's Creative Commons license, unless indicated otherwise in a credit line to the material. If material is not included in the article's Creative Commons license and your intended use is not permitted by statutory regulation or exceeds the permitted use, you will need to obtain permission directly from the copyright holder. To view a copy of this license, visit http://creativecommons.org/ licenses/by/4.0/

(C) The Author(s) 2021 